\title{
Diffusion or War? \\ Foucault as a Reader of Tarde
}

\author{
Sergio Tonkonoff
}

\begin{abstract}
The objective of this chapter is to clarify the social theory underlying in Foucault's genealogy of power/knowledge thanks to a comparison with Tarde's microsociology. Nietzsche is often identified as the direct (and unique) predecessor of this genealogy, and the habitual criticisms are worried about the intricate relations between Foucault and Marx. These perspectives omit to point to another - and more direct - antecedent of Foucault's microphysics: the microsociology of Gabriel Tarde. Bio-power technologies must be read as Tardian inventions that, by propagation, have reconfigured pre-existing social spaces, building modern societies. We will see how the Tardean source in Foucault's genealogy sheds new clarity about the micro-socio-logic involved in it, enabling us to identify some of its aporiae and to imagine some solutions in this respect as well.
\end{abstract}

\section{Keywords}

Foucault - Tarde - Genealogy - Power/knowledge - Invention - Diffusion - Device

\footnotetext{
${ }^{*}$ Tonkonoff S. (2017) Diffusion or War? Foucault as a Reader of Tarde. In: From Tarde to Deleuze and Foucault. Palgrave Studies in Relational Sociology. New York: Palgrave Macmillan, Cham
} 
In both Discipline and Punish and the first volume of The History of Sexuality, with prodigious historical archive work and dazzling prose, Foucault gives a detailed description of what are characterized as technologies for controlling time, space, and the body. These technologies are proposed as responsible for the formation of the main characteristics of Western modernity. As their deployment in the social space is mapped out, a series of no less impressive propositions are made about power, knowledge, and the subject in its reciprocal relations. Reticent when it came to submitting the results of this research as general theories, Foucault (1980b: 41) once characterized them as "philosophical fragments in historical workshops."

One of the first issues to draw attention in these texts was the postulate that the individual is one of the major products of the modern technologies of knowledge/power described therein. The post-structuralist subversion of the Cartesian subject takes on a sociological form in those pages, at the same time as it is sustained in specific and original historical analyses. Both books question the philosophical, juridical, political and economic conceptions that inform our common sense, while taking a step beyond the structuralism that dominated the intellectual scene in which they came about. The biopower theses would come to show that this individual is, in fact, a decentered construct, dominated by a societal order that it reproduces unknowingly. But this is not because $\mathrm{s} /$ he is a product of language in general (Levi-Strauss, Lacan), nor of ideology in particular (Althusser), but precisely because $\mathrm{s} / \mathrm{he}$ is constituted as a subject of these technologies.

It wasn't long, however, before the other side of these theses started to become clear to followers and critics: these technologies not only produce normalized subjects, but also normalizing societies. This may seem trivial and obvious, but if it is accepted, one would also have to accept that, regardless of what Foucault said in lessons, interviews, and even his own publications, what is at stake in this discourse on power is a social theory tout court. And this is so because it aims to reveal the mechanisms of production, reproduction, and transformation of societies in which individual normalization take place.

Thus, to test the internal consistency of this theoretical approach and its development possibilities, nothing is more important than to know how the technologies of power produce social ensembles and what types of ensembles these are. This amounts to saying that the Foucauldian discourse needs to answer such classic questions as what social groups 
are, how they are structured, and how they mutate. Foucault's contributions, like those of any other great thinker, could then be measured in relation to these questions. Given the radically historicizing clause that guided his research, these questions must be strictly dated and located. In other words, Foucault's social theory is at once and intrinsically a theory of Western modernity. But it's one thing not to make general ahistorical theories, and another to not make theories at all.

This could reactivate the reflection on what is essential and original about Foucault's intervention in this field. A possible answer is that it brings with it a particular approach to the social realm which has been called genealogy and microphysics. That both names are interchangeable will be read in what follows as the index of a double filiation present in this undertaking. The former refers ostensibly to the figure of Nietzsche as his great precedent. The latter leads to the never-mentioned, but no less important, work of Tarde.

To a large extent, it was against this work that sociology was established as an academic discipline in France - an establishment based on the theoretical and methodological Durkheimian framework. These bases, which can certainly be called rationalist, will find a new and sophisticated impulse in the positions of structuralism. Perhaps because of this it should not be surprising to discover that the reaction to these positions, which for convenience's sake can be called post-structuralist, found a highly important reference precisely in Tarde - just as important as the widely commented on influence of Nietzsche or Heidegger. This is at least true in the case of Deleuze, who read Tarde's texts in terms of an anti-Hegelian philosophy and an anti-Durkheimian sociology. As will become clear in what follows, it is also the case in Foucault's genealogical stage, and perhaps beyond it.

We shall see the new depth that some of the best-known genealogical formulations acquire if this "secret" Tardean filiation is accounted for.1 We shall also see that the genealogical discourse is much more theoretical, coherent, and generalizable than what it is commonly believed. And lastly, we shall see how both things cast considerable light on some of the aporias to which Foucault is drawn in the course of his research due to his Nietzschean choices - aporias that led to subsequent reformulations of his conception of power.

In re-examining Foucault's texts in the light of Tarde's sociology, it may be possible to better understand what these texts repeat on innumerable occasions: the bio-political technologies are inventions that have propagated in a capillary, infinitesimal or synaptic way, to the point of reconfiguring the pre-existing social space, giving way to normalizing societies and permitting their reproduction. Read through its microphysicist slant, this discourse undoubtedly bears the marks of a Nietzschean legacy (body/power/knowledge/ 
subjection/subjectification), but also shows that it is fundamentally related to the conceptual language devised by Tarde. That is, a language articulated by the following basic series: multiplicity-invention-imitation-opposition-propagation-ensemble. This series provides Foucault with the key of the genesis, organization, and transformation of social groups -although, as we shall see, he differs with Tarde in the issue of subjectification modes. In our view, this gives the virtual scope, and perhaps the current statute, of social theory to foucauldian genealogy. In any case, Tarde's microsociology must be seen as its "other source". The main purpose of the present chapter is to show this in its most relevant expressions.

\section{The Nietzsche Hypothesis (The War Model)}

The above-mentioned books, as well as the outer corpus of interviews, lessons, and writings that accompanies them, can - and we believe must - be read along the lines of the culture criticism program suggested by Nietzsche in On the Genealogy of Morality. There lie some of the major keys of the approach developed by Foucault in the 1970s. Above all, the understanding of the body as a multiplicity of anarchic forces and its connection with culture as a relationship of subjection, in which punishment is the privileged instrument of the production of subjectivity. Foucault reformulates, develops, and specifies these elements, problematizing this multiplicity of the individual body along with the multiplicity he also finds in the social body, and giving the name of technologies of power to the set of impersonal mechanisms that must deal with both types of multiplicities to produce societal order. Furthermore, Foucault historicizes, so to speak, Nietzsche's postulates in this respect. He discovers that the mnemotechnic described by Nietzsche - the spectacular and bloody punishments that make a memory in the "human animal" -is a fairly obsolete technology, typical of a type of power he calls sovereign. 2 The distinctive trait of modernity would, instead, be a bio-power where punishment is more of a normalizing exercise than ignominious branding.

It is well known that the methodological key of this (new) genealogy it is not so much asking what power is as how it works. This is, to avoid its treatment in terms of a transhistoric, universal, and immutable entity, but rather approach it as a historically variable and locally situated mechanism.

It is a perspectivist method that understands the knowledge of every human society as an integral part of the struggle for its production. And since that struggle brings with it the 
definition of what is (socially) true, it rejects all that in the traditional meaning of the word "theory" means neutral contemplation of objects of research - objects that are traditionally thought to be opposed to the subjects of knowledge, and universal in their ultimate structure. At the same time, this method is meticulous and primarily deals with minutiae. Instead of starting with the study of grand societal systems and/or great historical events, it searches the beginning of larger-scope transformations into the details of minor local occurrences. So, a genealogical analysis is always a micro-analysis. And given that its objects are the power/knowledge relations understood as relations between forces, genealogy is a social microphysics. But this is precisely its ontological key (the understanding of power as a relation of forces).

The emphasis on how it works rather than on what it is, then, cannot prevent the need to characterize in some way that whose functioning is being preached. Only that, in methodological terms, what it is does not seem to be a good starting question because our thinking habits lead us to answer that it would be a substance. This is impossible from the point of view of the ontology of difference that Foucault appeared close to from the late 1960s. From this point of view, the "object" of that predicate cannot be a substance (a "thing") but a relation - which radically modifies the form of construction of any object of research, and also puts in doubt whether one can continue to speak here of ontology. To say that power is a relation is to say that it does not exist as a substantial and unified instance. It deprives the word of its capital P to stop it being a macrophysical and totalizing concept, and to make it into an open, microphysical one. It also obliges one to spell it in plural (powers), because now it designates multiple, infinitesimal, local, and unstable, networks with no center, which are immanent to any organized social body.

Genealogy is, in fact, a method of approaching the socio-historical field both as a theory of its constitution and of its organization and transformations. In other words, it is a set of fairly connected hypotheses that bring together a series of ontological postulates and epistemological decisions from which Foucault's famous methodological recommendations are derived. That this theory seeks to be anti-scientificist and perspectivist; that it should stem from multiplicity and difference instead of unity and identity; that it should seek to recover suppressed knowledge to put it in conflict with theories with a capital $\mathrm{T}$; that it is, for the same reason, a theory with a small t (or a "minor" theory, in the Deleuzian sense); that with such operations, traditional questions and traditional answers about the social seek to be reformulated; all this does not make it less theoretical. If proof were necessary, one could note that, after describing his genealogical method in terms of its most polemical 
aspects, Foucault is forced to state: "I want to say this: in a society like ours, but ultimately in any society, there are manifold relations of power which permeate, characterize and constitute the social body" (Foucault 1980a: 94).

If this statement is taken seriously, its elements and logic have to be interrogated to specify what these power relations are, how they "permeate, characterize and constitute the social body," and what a social body thus constituted is. Regarding the first question, it is known that Foucauldian power relations do not refer primarily to relations between individuals, nor between individuals and structures (economic, religious, or political). Nor do they refer to relations of a force with another thing (a subject or an object), but a force with another force. Based on an abstract and differential conception of the force, presumably inspired by Deleuze's (1983) reading of Nietzsche, Foucault usually describes these relations as conflictive, local, reversible, and contingent. Its model is not the structure of the language, the contract, or the economy, but the hazard of war and its encounters.

However, the enumeration of the general characteristics of relations of force and the main methodologies of this analytics of power - both very well known and commented on cannot by themselves distinguish between the mode of constitution of a physical body, a biological body, or a social one. Nor can them show how the relatively organized social body we usually call society is historically constituted. Put in different terms, terms that mark Foucault's intervention and specific contribution on both points, the question would be: how to advance from a Nietzschean (and Deleuzian) ontology that posits that every body is a relationship of forces, to the socio-historical research of the modes of constitution and transformation of the social bodies in the specific context of Western modernity? Here is where clearly Foucauldian notions of technologies and devices of power find their place. But it is also here that Foucault makes use of concepts and logical articulations arising from Tarde's microsociology. It is necessary to point out the functions of these concepts in Foucault's genealogical discourse to complete its characterization, and to reveal the deficiency of the habitual reference to "Nietzsche, Genealogy, History" as a main text to describe and understand it. When Foucault did the essential but preliminary work of criticism and de-essentialization of the institutions that sustain Western culture, he based himself openly on Nietzsche. In this context he states that, instead of seeking out the "timeless and essential secret" of this institutions, it is important to understand "the secret that they have no essence, or that their essence was fabricated in a piecemeal fashion from figures from alien forms" (Foucault 1971: 148). But then, when he seeks to explain the specific socio-historical processes because of which that "piecemeal" construction took 
place, he recurs to Tarde's microsociologial grammar, without pronounces his name. This grammar forms a substantial part of his microphysics and of the turn toward the thinking of difference that brings with it.

\section{The Old Cartographer}

As we know, Tarde begins by understanding social life as an enormous number of small, simultaneous, and specific human activities which he classes into three types: imitations, inventions, and oppositions. What makes these activities social is that they are modes of inter-mental relation in which beliefs and desires are communicated by repetition, coadaptation, or confrontation. For Tarde, societies, groups, and individuals are made and transformed through these communicational processes. Here the production, reproduction, and mutation of any social system (including the individual) takes place in that multiple field made from the constant influx, convergence and divergence of currents of inter- or trans-individual beliefs and desires. Hence the very level, so to speak, of social life is the infinitesimal one. This is why this is a microsociology. Not because it studies only smallscale objects, leaving the analysis of large structures to a distinct and complementary macrosociology, but rather because, here, everything that appears as a large structure is nothing else but the generalization of a given way of doing, feeling, and thinking that was invented one day and has propagated imitatively ever since. That propagation gradually structures and partially homogenizes the social field in question, and gradually engenders, in the specific circuit of its repetitions, subjects of those structurations and homogenizations. This process takes place from individual to individual -though not necessarily face-to-face. Imitation is to Tarde (1903: 20) the "action at a distance of one mind upon another" in which an asymmetrical and reversible relation between a model and its copy is established, and whose multiplication produces what he calls imitative rays, flows, or currents. These currents are none other than the multiplied copy of inventions that have the tendency to scatter out as fashion and take root out of custom. Such is the way in which the frame of a given culture or society is configured. A creed, law, form of government, production, or trade is always the result of an invention spread locally, regionally, and even internationally, by acting as example - and which usually has lost in its spreading the marks of its origin. This is why Tarde, like Nietzsche, suggests that to discover the secrets of the great things one must interrogate their "low" beginnings. However, the lowness in question here is not moral but above all sociological and epistemological. This is not a matter of cruel, dishonest, or shameful actions, which 
therefore must be concealed, but of infinitesimal interactions in which new ideas and feelings take place and propagate quickly or slowly over variable distances. Thus, the microsociologist's work begins with the methodological execution of "archaeological digs, which reveal the filiation of successive inventions and trace their genealogical tree with irregular ramifications" (Tarde 1895e: 148).

The place where these inventions emerge would be always an individual, specifically, her/him brain. (There are no such things as collective consciousness or zeitgeist). But place here is neither cause nor source. Any invention of any kind - linguistic, military, industrial, aesthetic, etc. -happens in a mind fit to operate an unprecedented conjunction of preexistent imitative series that, by chance, meet each other in that mind. Therefore, in Tarde, there are no individual inventors, but a particular type of individuation: that which disposes a subject as the space of production of a new difference generated by a "happy interference" of imitative series, which until then have remained alien, incongruent, or even opposed. And this can happen in exceptional or ordinary individuals, whether famous or "very obscure."3

If these inventions are propagated, they will transform the social space through which they travel in a "brainly" or "synaptic" manner. To what is this possibility tied? The inventions that spread best are those that are the most fitting to a pre-existing socio-cultural configuration. This fittingness, which is not simple and which can only be partial, responds to certain "laws." We will come back to them later. For now, it is necessary to point out that the social success of an invention depends on its capacity for solving specific problems. To Tarde, inventions are (social) responses to social questions. Each of these questions or problems may bring about multiple inventions that come together to offer diverse solutions. In those cases, it can happen that some of them are contradictory and others complementary, both among each other and with preexistent social systems. When two inventions are opposed, their relation take the form of a "duel" - the meeting of symmetrically opposed forces in which neither prevails. This can last some time, "until the advent of some clear formula, from some suitable mechanism, which throws all the others into the background which serves thenceforward as the fixed basis for future improvements and developments" (Tarde 1903: 148). When a formula triumphs, it displaces its contemporaries, and substitutes, if that is the case, its precedents. But it can also happen that it co-adapts with another, so that instead of substitution there is "addition" among inventions. 
It is precisely this action of ensemble of scattered or even opposed imitative flows (coadaptation in the first degree), added to its capacity of addition to other ensembles (coadaptation in the second degree), that leads Tarde to give inventions the status of "social driving force" - instead of attributing them to negativity (psychoanalysis), contradictions (Marxism), or struggles (Foucault's Nietzsche). If imitations, by spreading, homogenize the social space, inventions diversify it and prevent it from closure. This is why they are the true agents of progress or evolution, as Tarde said in the Darwinian language of the nineteenth century. And for that reason they are, at the same time, capable of creating social harmonies. But these statements do not necessarily possess normative connotations, and less still imply a simple consensualist view of sociohistorical processes. This "progress" entails only the idea of contingent changes oriented toward an uncertain future, and its positive valuation lies in preventing the closing of the social field by existent repetitive circuits (produced by previous inventions). Regarding "harmony," it has to be said that in this theoretical model it is indifferent in terms of its content. It has to do with the ability of these co-adaptive ensembles to produce certain relative coherences in social practices, because they produce open systems in the social field.

This suggests that to give an account of all that makes it possible to identify a group as such (morals, laws, customs, forms of government), it is necessary to essay a genetic explanation. Or, more precisely, a polygenetic one. And this is so, because any social system is a set of co-adapted inventions proceeding from diverse origins. What we habitually call institutions are then "aggregates of inventions" (Tarde 1895d: 191). To know them, it is necessary to carry out a polygenetic and ascendant method of socio-historical analysis, one that follows the social processes in their transition from the small to the large, from the heterogeneous to the homogenous, from plurality to unity, from the heterarchical to the hierarchical, from the local to the global. This is a method that always begins from different localizations, and always goes from the micro (complex and heterogeneous) to the macro (homogenous and standardized), undertaking from there its path back to a recursive and virtually interminable process. Tarde promotes this method of knowledge because he believes this is the form of composition of social reality itself. This method recognizes the impossibility of finding the unique and absolute origin of any social processes. Social life, we are told, can only be attained "by the medium": there are no ex nihilo inventions; they are all unprecedented conjunctions of pre-existing truisms. And given the multiplicity of existing inventions, an unique directions of history, a single History, it is not possible. There is also the impossibility of its ending. Since the coupling of imitative series is 
contingent, the transformations of the law, religion, politics, or economics are not predictable in either evolutionist or dialectical terms. History, "that tangled skein ( . . ) or rather, that confusing mélange of multi-colored skeins" (Tarde 1895b), is not made up of a single drama but innumerable scenes of duels, conjunctions, and propagations, multiplied on various scales. Stories, then, heterogeneous and multifarious, that weave the weft of the social field, sometimes in communication between them, other times not.

Because of all this, this microsociology implies a criticism of the concepts that only show the "final" results of the process they study, and that also do so incorrectly, as they tend to reify those results and place them as primary causes. Society, State, Nation are some of these concepts - as is Power, as Foucault will add in turn. Tarde calls them "panoramic" concepts, suspects them of medieval realism, and accuses them of hiding what it is necessary to uncover. For him, if they designate something, it is, in fact, the product of the generalization of formulae, techniques, or dogmas that have propagated imitatively, and what has thus propagated was created in a given time and place by (or in) a certain individual.

To Tarde, every social process gets traction from this double mechanism (inventionimitation) that prevents it being trapped into closed systems for ever, as much as prevents the total homogenization of the space in which it occur. But, as we saw, there is still another type of social relation possible in the Tardean social life, albeit subordinated to the other two. It happens that models propagated can co-adapt between them and produce inventions, or interfere and produce oppositions. In general, according to Tarde, there is no demonstration that does not recruit demonstrators, both for and against. The opposition then would be nothing else but a counter-model, a particular manner of repetition and not a difference (differences, precisely because they are different, could not oppose each other). Hence, Tarde understands there are two ways of imitating: proceeding faithfully like the model, or doing exactly the opposite. Those who affirm and those who deny are tightly connected through their confrontation around the same ideas or desires. Consequently, the counter-imitation also produces similarities - both between those who associate together to affirm and those who do so to reject, but also between both groups, as they affirm or deny the same things. Only inventions (true differences) manage to break out of the circuit of the reproduction of similarities and counter-similarities. There is, then, a marked imbalance between the two former forms of social interaction (imitation and invention) and the latter (opposition), which proves intermediate and subordinate, because the struggle would always be the middle point between mimetic progression and invention. 


\section{The New Cartographer}

If we now attempt to get from the Foucauldian corpus answers to the fundamental questions of social theory - that is, how social groups are produced, reproduced, transformed - we could start with one of the few explicit formulations to be found in this respect in Discipline and Punish. Here we read that "every system of power is presented with the same problem," and this problem is "the ordering of human multiplicities" (Foucault 1995: 218). This seems to be the true starting point when we try to clarify the theoretical logic that articulates the historical and sociological framework in this genealogical discourse. Human multiplicities are the field in which - to say it in nietzschean language - coercive (memo) techniques produce both "morals" (norms of societal organization) and "animals capable of promising" (subjects subjected to those norms). However, as mentioned earlier, what in Nietzsche was the trans-historic mode of production of the social body and subjection of the individual (the mark), becomes in Foucault the central trait of a clearly dated power technology: pre-modern sovereignty. In contrast, the essence of modern bio-power would not lie in marking bodies, but in exercising them as individuals and regulating them as populations.

These technologies of power/knowledge have a beginning that is low, trivial, and obscure, in the sense expressed in Nietzsche, Genealogy, History. Even when they arouse noble, humanitarian ambitions, even when their ends may pass as the most elevated of the culture (educating, for example), the genealogical view reveals these technologies to be a set of devices assembled with purposes of raw domination. However, in Discipline and Punish, those beginnings are no longer Nietzschean "fate of struggles" but "tiny inventions" such as Tarde conceived them. Power technologies are ensembles of microscopic creations of diverse precedence, whose emergence does not come about from fight but rather from coadaptation. 4 And this continues thus in the first volume of The History of Sexuality, where bio-power is explicitly presented as a second-grade ensemble or device. There, the anatomo-politics and bio-politics, each of them being a co-adaptation of inventions, have in turn co-adapted to produce bio-power (Foucault 1984). If the minimum definition of device is a "resolutely heterogeneous set" of elements, it is clear now that those elements are inventions, and that as such they do not come about from subjugation in battle or from synthesis of contradictions. Nor do they arise from a collective consciousness or derive from a vague zeitgeist. They take place in specific, identifiable individuals, whom Foucault identified wherever possible. Thus numerous inventors, some notable and most unknown, 
are consigned in his archives: J. Bautista de la Salle, a famous priest and educator; but also Charles Demia, a cleric who created a regulation to introduce the hierarchic surveillance in schools; or Jacques de Batencour, an abbot who wrote L'escole paroissiale - a treatise of methodical instruction for parochial schools. Foucault laboriously exposes the polygenetic, multicentered and accumulative character of these inventions. But he also places at the center of the socio-historical dynamic he describes what in Tarde is the cipher of all invention: they are specific responses to problems, and even to specific "matters of urgency" (Foucault 1994b: 229). In this case, those that seek to resolve the "problem of accumulation and useful management of men" (Foucault 1995: 303).

Bio-power, then, would be the general name of a set of inventions "of different origin, of disseminated localization" that, co-adapted, constitute the devices intended to tackle the problem of ordering social multiplicities as presented at a specific historical crossroads: that would lead to the societal configuration we know as modern, and which Foucault characterizes as normalizing. The specific challenge of bio-power would be to articulate the needs of reproduction of capital with the production of submissive workers. Or, in more comprehensive terms, its challenge was to functionally compose obedience with productivity; or even to transform the multiple heterogeneity of bodies in normal individuals and healthy populations. And given that, in Foucault's opinion, bio-power has achieved in great measure these objectives, he has no doubt about considering it as a group of genial inventions. (This is the case at least in the case of disciplines, the power technologies that he called "Columbus's egg" in the order of politics.)

Generally speaking, these are mechanisms or devices intended to have "the precise role of introducing insuperable asymmetries and excluding reciprocities" in the social field, understood as a multiple space of power relations. Relations that those devices seek to "unbalance definitively and everywhere," producing the irreversible subordination of some individuals to others (Foucault 1995: 205). But for this to happen they must "colonize" the social field in question. That is, they have to spread. And that spreading is Tardean in all its major traits. What is spread are technologies in terms of schema or models. These technologies, arising from the progressive co-adaptation of heterogeneous procedures, instruments, and knowledges, are configured as bundles of easily transmissible techniques and formulae, aimed at "programming" on the level of their elemental mechanisms the basic functioning of a society. They are expansive models that, remaining equal to themselves, are disseminated weaving a microsociological tissue, establishing a "synaptic" power regime in the social field. Thus, "the panoptic schema, without disappearing as such 
or losing any of its properties, was destined to spread throughout the social body; its vocation was to become a generalized function" (Foucault 1995: 207). This propagation comes about by following variable rhythms, speeds, and distances. And it is a fundamental task of the genealogist to follow the chronology of these inventions as much as the calendar of these diffusions (Foucault 1984). In other words, she must map the multilinear alternatives out of which these technologies arise at one point, circulate in irregular networks, and become "general formulae of domination" that come to impose themselves on others. That is, to produce and reproduce societies of normalization where, before, there were societies of sovereignty.

As for the "laws" of this diffusion, Discipline and Punish seems to recognize just one: those inventions that prove more efficient in increasing the productive potential of the bodies and diminishing their political capacity propagate the best.5 We shall see some of the consequences of this. For now, let us say that this law causes us to reconsider, along with the very well-known (Nietzschean) relations between the knowledge/power and the body, the less commented upon (Tardean) relations between technologies of power. The Tardean prism shows that when it is a question of describing the dynamics that has led to the configuration of modern societies, the truly relevant struggles in this genealogy occur not so much between bodies as between technologies (which is the same as saying, inventions). Technologies oppose each other, coming together to respond to the political problem that constitutes the scenario of its emergence and propagation. The "duel" takes place in the social field and the winning technology will control the bodies that, at least in this Foucauldian period, prove frankly passive. Thus, for example, in the last half of the eighteenth century, three technologies faced each other, presenting themselves as opposed forms of dealing with social multiplicity in rising capitalism: one sovereign, one juridical, one disciplinary.6 No synthesis, open combat or catastrophic destruction resulted from this opposition. Instead, the outcome was a certain functional complementarity. Since then the disciplines have worked as a "counter-law" that set the normalizing rules before or behind the contractual codes, establishing asymmetries where the latter advocated equalities (Foucault 1995: 222).

This is clearly a non-dialectic concept of opposition, in which conflict is a particular type of complementarity and counter-similarity. And perhaps most importantly, it involves a nondialectic notion of social change through which Foucault, like Tarde and Deleuze, seeks to give an account of the socio-historical transformations in general. The grammar of infinitesimal difference attempted by all of them understands that transformations come 
about from inventions: differences that are produced and disseminated at a level called microphysical (Foucault), microsociological (Tarde), or micropolitical (Deleuze), and irremediably modify the social space in which they are propagated.

However, it is legitimate to wonder about the breadth and depth acquired by the grammar of infinitesimal difference in these socio-historical analyses by Foucault. This inasmuch as they ultimately offer an image of modernity whose steely, nuance-free grey tends to ignore the existence of diverse contemporary socio-historic spaces and times, and where a hyperfunctionalist description of the bio-political diffusion prevents both the effectively existent "differentials of modernity" and the possibility of alternative historical developments from being shown. This may be especially true in Discipline and Punish, where the passivity attributed to the bodies, the absence of a theory of subjectification, the equivalence between subjectification and subjection, along with the total homogenizing efficiency ceded to the action of power devices, transforms the description and the analysis of the "prison society" in the theoretical (and political) confinement of the genealogist.7

\section{Tardean Solutions To Foucauldian Problems?}

The notion of diffusion appears in the key moments in which Foucault (1995: 209) seeks to show how "the formation of what might be called in general the disciplinary society" takes place. This indicates that, in this microphysics, as in Tarde's microsociology, diffusion is not something that can be circumscribed to certain specific areas of social life. Therefore, it would be incorrect to elaborate about them equally specific forms of knowledge and analysis ("regional" theories and methodologies). In short, diffusion is here a constituent process of the social organization tout court. This leads both authors to assume that it is possible to reconstruct the history of a culture based on the movement of inventions in time and space. However, in Foucault's work this issue is never explicitly dealt with. If one were to advance on it as a way of casting light on the previously indicated aporias, it could be claimed that at least four fundamental questions are implied in the postulate of the diffusion of inventions as a mode of production and transformation of social ensembles: (I) What are the "internal" mechanisms of diffusion? (II) What might be the relations of the different lines or flows of diffusion between them? (III) What might be their relations with the pre-existing social space? (IV) What might be the results of their deployment in such a space?

Regarding the first of these questions, it is known that, in Foucault, the technologies of power are procedures and knowledges that subdue bodies, subjectifying them and relating 
them with others in a regulated, hierarchical way. In this manner they configure organized societal ensembles. But technologies must spread for all this to happen, and the mechanisms of that propagation can only be psychic, or rather, inter-psychic. However, Foucault's genealogical texts have obviated this problem or have treated it with the method of the black box. This method, in addition to its near-physicist emphasis on the value of space as an organizer of conduct ("stones can make people docile and knowable"), and the passivity attributed to the bodies ("surface of inscription of the events"), has earned him more than once the qualification of behaviorist. As for Tarde, surprising though it may seem, in his work there are no more than a few sketches of a theory of the psychic apparatus, and although it is possible to find in his work a theory of the individual (or indeed various theories), problems such as cognition, memory, feelings, and affects are only ever approached fragmentarily. In sum, if for one the beliefs and desires, and for the other the relations of power, pass through and upon the individuals and constitute themselves as such, neither of the two can explain how that "fold" occurs, how it works specifically, and how it "unfolds" in interpsychic relations.8 This does not prevent them from understanding diffusion as a general social dynamic, a force productive and reproductive of social groups and of subjects subjected to them. The difference is that Tarde speaks clearly of the psychic monad as naturally mimetic, and Foucault forbids himself any hypothesis in this respect.

As for the second and third question, Foucault makes it clear that, in his opinion, technologies spread in competition with each other, that they can articulate with each other, and that the prevalence of the victors will not make the others disappear but rather complement them - at least in certain specific aspects, and at least in the cases he studies. But he says almost nothing of the variable or "differential" result of the spread of technologies on social spaces colonized by them. This result is necessarily dependent on the diverse socio-cultural textures on which they propagate, and on the differential reaction of each of them to this advance. Once the competition is resolved in terms of capacity for solving a problem or socio-political emergency, the Foucauldian model seems to suppose a complete efficiency of diffusion in terms of homogenizing potential. This prevents thinking, for example, about different types of normalizing configurations as the "final" result of the process of propagation of bio-political technologies.9 Thus, regarding the fourth question, the Foucauldian discourse can be qualified as at least ambiguous, as it is not possible to know whether it is describing technologies only as they were projected by their inventors and/or their real impact on social spaces. However, references to the 
disciplinary society as the general result of the diffusion of "carceral mechanisms" tend to strengthen the second option. Also, here, the model of war seems to dominate the panorama with burdensome results - perhaps faulty in their own terms - as it presents colonizing technology as a force that subjugates others without compensation, without mixing, and without concessions from it.

There is always, it is argued, resistance to power. That is why it can only be thought in relational terms. But the transformations that technologies necessarily suffer in their deployment are never, or almost never, recorded, nor is their becoming something else with respect to their initial structuration and objectives. This relational perspective tends to assume a one directional form that prevents conceptualizing the "final" configuration of any meta-stable systems of domination as strongly dependent on the resistance it encounters on the path of its configuration, and those it suffers during its existence.

In accordance with this, the historic Foucauldian account tends to present the structuration processes of modern social societies in terms close to acculturation. That is, it tends to harbor the supposition that the model that has spread is accepted completely as it is by those on which it is imposed. Invariably safe from any contamination, the model always remains intact, as only the colonized social space is modified by reconfiguring itself as the almost exact image of the model. Thus, the story of disciplinary propagation in Discipline and Punish leads us to a situation in which not only the captured bodies are fundamentally passive: so, too, is the social field in which technologies spread.

In the case of Tarde, as imitation is the elemental mode of the social relation, the efficiency of diffusion is also supposed to a great extent. It is also true that in almost all his canonical definitions of imitation, he treats the imitated model as a photographic negative that is transmitted intact from one individual to another. However, Tarde also proposes a broad elaboration of the processes of imitative dissemination that makes his work still today a major theoretical reference in this matter. A brief review of his "laws of imitation" will allow us to pinpoint a little more this contrast. It will also show us more clearly the options taken by Foucault, allowing us to complete this sketch of immanent criticism of some of its sociological consequences.

According to Tarde, some inventions can become diffused while others cannot. But why only some of thembecome diffused, if all inventions have a "vocation of infinite" and can, by rights, expand? In other words, what are the laws of imitation? There appear to be two types of law, some logical and others extra-logical, and both show the relational and stratified (to use Deleuze's word) character of the social field. The former claim that it is 
central in the actualization of an invention's chances of spreading, its compatibility with some beliefs and desires already present in the medium where it seeks to be diffused. In this respect, every socio-cultural space would have the socio-cultural epidemics that logically correspond to it. This is true for the spread of new governmental, economic, scientific, and religious practices, as much as it is for new words, hairstyles, or dresses, and even for new types of murder, theft, or fraud.

As for the extra-logical laws by which an invention can be spread or not, they show that also, for Tarde, the problem of diffusion is inextricably tied to power. So the "cascade principle" says that those inventions arising from - or that have been adopted first by focus points considered socially, politically, or culturally superior will have the best chances of spreading. Note that this influence "from above" does not imply a societal topography in which certain instances (representations, dominant classes, or State) are "outside" the social field they dominate. And this is so, because the social field in Tarde, like in Foucault and Deleuze, has no outside. It is rather a "flat" field, or perhaps an undulating one, where local asymetric relations are woven into nets producing trend effects - or "effect d'ensemble," in Foucault's words. A second type of extra-logical condition for mimetic spread is tied to the existing distance between the focus point and its receivers. According to this principle, the degree of influence of a model will increase proportionately to the closeness to it. Hence the importance Tarde attributed to small groups and the form of communication that characterizes them: conversation. Tarde saw in the family the medium for the reproduction of traditions, and in cafés, and social, scientific, and literary meetings, the most fluid scenario for the imitative spread of fashions. But here the close model is not only that which occurs face-to-face. Tarde was one of the first to recognize the emergence and importance of the mass media and its role in the reduction of psychological distances in the global social space.

But even in the best logical and extra-logical conditions, Tarde alerts us to the fact that what is really produced is a hybridization, in variable degrees, between that which spreads and cultural configurations where this occurs.

Thus, for example, speaking of the Francophilism of some sectors of the Russian elite, he claims that if this imitative current were to become widespread, if this range of influence of wanting to do like the French were to widen, the Russian social space would take on a new cohesion. To a certain extent the plurality of previously existing dialects, customs, uses, ideas, and techniques would become homogenized, and "this new Russia would be like, one might say, a new France, but very different from the old one. Because having been 
refracted in this other medium, the French things would have been made more Russian because of it, just as the Russian will have been made more French" (Tarde 1895a: 20). The concept for this relation is, once again, that of co-adaptation or ensemble.

\section{The Tarde Hypothesis}

Foucault's quotation policy has always drawn his readers' attention. When asked about this, he once claimed he used the authors that mattered most to him without quoting them. However, he paid tribute on numerous occasions to Nietzsche, and justified his uses of Marx several times. When it came to Tarde, Foucault obeyed his own rule to the letter, using Tarde's microsociological grammar without ever quoting him. As we have seen, this grammar serves as the framework for his genealogical discourse, at least when taking as it subject the dynamics of production and reproduction of modern societal ensembles. Handling this micro-socio-logic skillfully, Foucault identifies and describes a series of differents inventions (hierarchical surveillance, normalizing sanctions, examination, panopticon, confession, psychoanalysis) and, showing it gradual assembly in technological devices oriented at specific ends (panopticism, the sexuality device), he sketches the map of their spread. He also adds that, in that propagation, such devices could asmuch oppose each other as co-adapt with each other. This propagation is here, as it is in Tarde, an "action at a distance" placed on the infinitesimal level of social life, capable of generating systems of regular behaviors with certain goals, and whose general result is no less than the configuration of organized social bodies. So, also in this genealogical discourse, the doublemechanismof invention/diffusion constitutes the specific form of production, reproduction, and transformation of societal groups.

As for the multiplicity on which the devices in question are deployed, this is a "moving substratum" of power relations understood as relations of force that weave the social field. It is possible, as Patton argues (2000), that Foucault understands the ontological statute of those relations of force guiding Deleuze's reading of Nietzsche. But as we have seen, it is indubitable that in addition, and fundamentally, he seeks to establish what is the specific form of constitution of the social bodies. This task then cannot be carried out in the abstract, but must be performed by characterizing relations of force in the social level as relations of power, and showing how they are configured differently in every era - or rather how each distinct configuration produces different eras. As is known, the response Foucault formulates to these requisites, and by which he has gained an unavoidable place in contemporary social theory, is that technologies of power are the specific devices that 
"make society," and that different technologies make societies (and subjects) with different characteristics. These technologies organize the unstable network of power relations, unbalancing it, establishing its hierarchies, its strategic directions, its circuits of reproduction, producing subjectifications and constituting, in this way, a societal body. But to say this is also to show that it is in Tarde that Foucault finds the (micro) sociological grammar that allows him to go from the treatment of force and power relations in general to the "workshops of history." He borrows on this grammar to establish how mobile and dispersed power relations are systematized and reproduced, and how they can come to design the general configuration of a determined societal type according to the prevailing technologies or devices at work.10

However, it is clear that the Nietzschean vector remains present here, and indeed dominates, at least for two reasons. First, because this is not a matter of technologies in general but technologies of power: they are "political" inventions in a very definite and quite restrictive sense. The Foucauldian inventions are coercive inventions, and such coercion would be decisive in the process of (re)production of individuals and groups, while in Tarde this is possible by means of imitation/suggestion, even (and especially) when this is a matter of power relations.

We have seen how the concept of imitation and the treatment of diffusion conditions indicate that also for Tarde the elemental social tie is that of dominator/dominated. But this does not mean that for him exploitation, (physical) force, subjugation, and injury constitute the "fundamental principles of society" and even of life - as in Nietzsche's aphorisms (1968) that inspire Foucault the genealogist. It means, rather, that this tie is generated by way of fascination. In this lies the core of the "Tarde hypothesis." Its model is not war, but hypnosis. As stated, the social field is here a multilinear and unstable network of imitations which constitute - along with oppositions and inventions - the fabric of every societal system. And this is a purely communication process based on suggestion (no matter how obscure this notion may be). Hence, something in the order of enchantment would be essential also in power relations (in the narrow sense of the expression: colonizer/colonized, for example), if they are to last. It is not that Tarde denies the social role, and the overwhelming historical presence, of coercions of any kind. It is that if this role were first and prevalent in the societal configuration, the struggle would have to be given the central (ontological, sociological, and political) role that he refuses to concede to it. 
All this allows us to conclude that Tarde's microsociology is the "other source" of Foucault's genealogy. Foucault borrows its three key concepts (invention-diffusionopposition) to frame his own sociohistorical discourse, especially when formulating his thesis about production and reproduction processes of modern societies. But in regards to the crucial problems of the general characterization of power and of the forms of subjectivation, this source is as important as subordinated. The Nietzschean options assumed in both capital matters go against that microsociology. Likewise, it is necessary to point out that Foucault's use of the latter does not ever appear to have been either complete or uncritical. And it would still be possible to speak of at least two important "corrections" by Foucault to that grammar: the removal of its last anthropomorphic and psychologistic traces, and the inclusion of an epistemological reflexivity that in Tarde was absent or blurred.

Having said that, it is indubitable that there is common ground between both Tarde's and Nietzsche's hypotheses. There is an in-between land that allows coexistence and even complementarity, in certain aspects, among them. That common ground is the relational thinking of the multiplicity and the difference. In the area of social theory this means, above all, postulating the existence of a multiple and heterogeneous social field that exceeds societal (and subjective) orderings produced, reproduced, and transformed therein. Tarde has a biological metaphor for this: in terms of social life, he says, the tissue always exceeds the organs. Then, in the starting point of both hypotheses, there is a social multiplicity conceived as a field of forces - but in one these forces are mostly coercive/productive and in the other hypnotic/productive. This also means the exigency of a microsociological approach to this multiplicity. Not as a method concerned only, nor fundamentally, with face-to-face interactions, but rather as an ambitious theoretical attempt to produce a novel description of social processes and structures of different scales beginning by the infinitesimal of relation of forces, precisely.

Regarding the non-complementary tensions between both positions, there are indications that some of the aporias of the genealogical period seek to be saved by Foucault through new explorations in the path opened by Tarde. This is visible, for example, in the recurrent use of the expression "action at a distance," present in the reformulation of the concept of power in terms of governmentality. This reformulation can be read, at least in part, not only in terms of the use of Tardean grammar but also of an elaboration of the concept of imitation as action capable of assuming multiple modalities. It is true that for Foucault this is not the action of one mind over another as in Tarde, but above all over other actions. 
Thus, he maintains, at least on this point, the near "physicist" or, in any case, nonpsychological bias of his genealogical approach - a bias according to which actions over space continue to be favored over (direct) actions over the "mind." Nevertheless, his attempts do not exclude the mention of modalities such as "orientation" and even "leadership" (Foucault 2007). In any case, Tarde's microsociology offers to the last Foucault, as well as offering to us, some important insights to maintain the rejection of the body as a biological reserve of freedom, and continue to think about the subject as a complete result of social practices. But it allow to do so without equaling subjectification with coercive subjection, and the coercive subjection with politics.

\section{Notes}

1. Deleuze was the first one to point out the necessity of comparing Foucauldian microphysics and Tardean microsociology (and also Bourdieu's sociology of strategies). "Here we ought to contrast Foucault's thought with Pierre Bourdieu's sociology of 'strategies', and ask in what sense the latter constitutes a microsociology. Perhaps in turn we ought to contrast both these forms of thought with Tarde's microsociology" (Deleuze 1986: 142).

2. Nietzsche summed up this mnemotechnic and its functions as follows: "How do you give a memory to the animal, man? How do you impress something upon this partly dull, partly idiotic, inattentive mind, this personification of forgetfulness, so that it will stick? . . This age-old question was not resolved with gentle solutions and methods, as can be imagined; perhaps there is nothing more terrible and strange in man's prehistory than his technique of mnemonics. 'A thing must be burnt in so that it stays in the memory: only something that continues to hurt stays in the memory' - that is a proposition from the oldest (and unfortunately the longest-lived) psychology on Earth”. (Nietzsche 2007: 38)

3. "However, do not confuse my thought with the great man theory. In my view, what conduct the world are not great men, but great ideas that nest in little men. A mass of fruitful inventions (the one of the cero, or the gunpowder) are anonymous; they emanate from obscure individuals ..." (Tarde 1902a: 562).

4. Foucault stated this in strictly Tardean terms: The "invention" of this new political anatomy must not be seen as a sudden discovery. It is rather a multiplicity of often minor processes, of different origin and scattered location, which overlap, repeat, or imitate one another, support one another, distinguish themselves from one another according to their 
domain of application, converge and gradually produce the blueprint of a general method. (Foucault 1995: 138)

5. Foucault makes an extensive use of another Tardean law in the first volume of The History of Sexuality: the "cascade" principle. This principle plays a major role in the explanation of how the modern devices of control (and production) of sexuality was "elaborated in its more complex and intense forms, by and for the privileged classes, (and) spread through the entire social body." As Foucault himself puts it: "If one writes the history of sexuality in terms of repression, relating this repression to the utilization of labor capacity, one must suppose that sexual controls were the more intense and meticulous as they were directed at the poorer classes; one has to assume that they followed the path of greatest domination and the most systematic exploitation: the young adult man, possessing nothing more than his life force, had to be the primary target of a subjugation destined to shift the energy available for useless pleasure toward compulsory labor. But this does not appear to be the way things actually happened. On the contrary, the most rigorous techniques were formed and, more particularly, applied first, with the greatest intensity, in the economically privileged and politically dominant classes. ( . . . The bourgeoisie began by considering that its own sex was something important, a fragile treasure, a secret that had to be discovered at all costs ( . . ) For their part, the working classes managed for a long time to escape the deployment of 'sexuality'. ( . . . ) As for the mechanisms of sexualization, these penetrated them slowly and apparently in three successive stages" (Foucault 1984: 120/121).

6. Foucault summarizes this as follows: "In any case, it can be said that, in the late eighteenth century, one is confronted by three ways of organizing the power to punish. The first is the one that was still functioning and which was based on the old monarchical law. The other two both refer to a preventive, utilitarian, corrective conception of a right to punish that belongs to society as a whole; but they are very different from one another at the level of the mechanisms they envisage. ( . . .) We have, then, the sovereign and his force, the social body and the administrative apparatus; mark, sign, trace; ceremony, representation, exercise; the vanquished enemy, the juridical subject in the process of requalification, the individual subjected to immediate coercion; the tortured body, the soul with its manipulated representations, the body subjected to training. We have here the three series of elements that characterize the three mechanisms that face one another in the second half of the eighteenth century". (Foucault 1995: 130/1).

7. On this point see Deleuze (2003). 
8. This is true for the "genealogic" Foucault, but it does not seem accurate for the "ethic" one. And, perhaps, all this last period of his work can be read precisely as an answer to that problem. Regarding the individual "unfolding", Tarde has mostly focused on her/his occurrence in the crowd and the public (see chapter "Individuals, Publics, and Crowds. Where Does Social Change Come From?" of this book).

9. Thus, for instance, what kind of panopticon is a Latin American (panoptical) prison, which is invariably overcrowded? Saying that it is an underdeveloped disciplinary device would not help much, and it will replicate, in this theoretical context, the Eurocentric fallacy that sees deficient applications of the central model in any other type of societal functioning. Instead, doesn't it give an account of the cultural thickness of the social formations that received that invention "from the North"? Wasn't this invention modified by its travel to other lands at the same time it modified them? This is not only an empirical problem. It concerns the existence, or not, of concepts that enable us to think social life as truly relational and as iterative processes - namely, thinking social life from the point of view of a paradigm of infinitesimal difference. A paradigm in which Foucault's work plays, certainly, a very relevant role.

10. Therefore, it is possible to relativize some opinions according to which "the microphysics of power explains neither how multiple and disperse power relations assume a certain 'coherent' or 'unified' form, nor how they traduce in more or less global strategies or social hegemony, which can in turn act on societal micro-powers" (Lemke 2004: 16). This could be valid if Foucault's genealogic approach was, so to speak, one-dimensional, and if its sole dimension was Nietzschean. But, as we have tried to show here, not one but two main "hypotheses" support this approach. Or, maybe, it can be said that one Nietzschean hypothesis and one Tardean grammar are at stake here. The last one is the one which gives an account of the Foucauldian view of society's constitution.

\section{Bibliography}

Deleuze, G. (1983) Nietrsche and Philosophy. New York: Continuum.

Deleuze, G. (1986) Foucault. París: Minuit.

Deleuze, G. (2003) Deux régimes de fous. Textes et entretiens 1975-1995. Paris: Minuit. 
Foucault, M. (1971) Nietzsche, la genealogie, I'histoire. In Hommage a Jean Hyppolite. Paris: Presses Universitaires de France, pp. 145-172.

Foucault, M. (1980a) Power/Knowledge: Selected Interviews and Other Writings 1972-1977. Translated and edited by Colin Gordon. New York: Pantheon Books.

Foucault, M. (1980b) Débat avec Michel Foucault. Table Ronde du 20 Mai 1978. In Michelle Perrot (ed.) L'Impossible Prison. Paris: Seuil.

Foucault, M. (1984) The History of Sexuality. Vol. I. New York: Pantheon books.

Foucault, M. (1994b) Le jeu de Michel Foucault. In D. Defert y F. Ewald (eds.), Dits et écrits: III: 1976-1979. Paris: Gallimard, texte $\mathrm{n}^{\circ} .206$.

Foucault, M. (1995) Discipline and Punish: The Birth of the Prison. New York: Vintage.

Foucault, M. (2007) Security, Territory, Population: Lectures at the Collège de France, 1977-1978. New York: Palgrave Macmillan.

Lemke, T. (2004) Marx sans guillemets: Foucault. la gouvernementalité et la critique du néolibéralisme. Actuel Marx, 2 (2), pp. 13-26.

Nietzsche, F (1968) Will to Power, trans. W. Kauffmann and R. J. Hollingdale. London: Weidenfeld \& Nicolson.

Nietzsche, F. (2007) On the Genealogy of Morality. Cambridge: Cambridge University Press.

Patton, P. (2000) Deleure and the Political. London: Routledge.

Tarde, G. (1895a) Monadologie et sociologie. In Gabriel Tarde (ed.), Essais et Mélanges Sociologiques. Lyon: Storck, pp. 309-390.

Tarde, G. (1895b) Questions sociales. In Gabriel Tarde (ed.), Essais et Mélanges Sociologiques. Lyon: Storck, pp. 132-158.

Tarde, G. (1895d) La Logique sociale. Paris: Alcan.

Tarde, G. (1895e) Le postulat de le sociologie. Revue philosophique, LI, pp. 661-664.

Tarde, G. (1902a) L'invention considérée comme moteur de l'évolution sociale. Revue Internationale de Sociologie, 7, pp. 561-574.

Tarde, G. (1903) The Laws of Imitation. New York: Henry Holt and Co. 